\title{
The trientine crisis in Canada: A call to advocacy
}

\author{
Natasha Chandok MD MPH FRCPC ${ }^{1}$, Eve A Roberts MD MA FRCPC ${ }^{2}$
}

W ilson disease (hepatolenticular degeneration) is eminently treatable. Patients who receive an effective treatment consistently, and tolerate it well, enjoy prolonged, reasonably good health. However, an estimated $20 \%$ to $40 \%$ of Wilson disease patients cannot be maintained on D-pencilliamine due to myriad severe side effects, including immediate hypersensitivity reactions, nephrotic syndrome, bone marrow toxicity and early neurological deterioration $(1,2)$. The disastrous effects of stopping treatment completely in Wilson disease are well-documented. The literature and web media contain heartwrenching anecdotes of copper reaccumulation culminating in hepatic or neuropsychiatric deterioration, including death via liver failure. Although some Wilson disease patients may achieve stability with zinc monotherapy either as first-line treatment or following chelation therapy (3), such an approach may be inadequate - even potentially dangerous - for a subset of patients because hepatic copper concentration typically remains unchanged during chronic treatment with zinc in pharmacological doses.

Trientine, an alternative oral chelator that removes tissue copper and enhances renal excretion of copper, is suitable in patients with contraindications to D-penicillamine, is as efficacious as D-penicillamine at appropriate dosages and is associated with significantly fewer side effects (4). Most importantly, trientine is recognized as a lifesaving medication for the subset of Wilson disease patients who require chelation therapy but cannot tolerate long-term D-penicilliamine (5). As of January 1, 2014, Valeant Pharmaceuticals, the North American manufacturer of trientine (trade name 'Syprine'), terminated its program whereby Syprine was made available to Canadian patients with Wilson disease at no cost and simultaneously changed its price from approximately $\$ 800$ per 100 tablets to approximately $\$ 11,000$ for 100 tablets. Because Syprine lacks a drug identification number, third-party payment is not available. Clearly, continued treatment with Syprine will not be a financially viable option for most patients. In effect, trientine is no longer available in Canada. Some patients may be transitioned successfully to zinc, but the vast majority have been prescribed trientine because of D-pencillamine intolerance and many have also already failed a trial of zinc. Thus, they find themselves in a hopeless situation similar to that of Wilson disease patients in the 1940s or, indeed, in 1912. Many would agree that this utter travesty simply cannot be allowed to unfold.
It is astounding that Canadian patients with a rare but treatable genetic disease are left in this predicament. A possible consideration is that Canada lacks an orphan drug policy inclusive of dealing with similar situations; however, the current version of such legislation under consideration would not necessarily head off this sort of problem. Treatments for rare diseases have become an attractive niche market for pharmaceutical companies, and pricing is typically based on what it is believed the market will bear. In fact, the situation with trientine is not clearly covered by the envisioned legislation. Immediate vigorous advocacy by the Canadian medical community, in particular the readership of the Canadian Journal of Gastroenterology and Hepatology, is urgently required. The Canadian Association for the Study of the Liver can take a leadership role. It should not be lost on this Journal's readership that many liver diseases qualify as rare diseases (on the basis of prevalence data), not just Wilson disease. The plight of Wilson disease patients who absolutely require trientine demands immediate action, but the well-being of other Canadian patients with liver disease may also be at stake. A recent analogous, although by no means identical, situation with colchicine in the United States provides a cautionary tale (6). Given these complex issues regarding drug pricing, Canadian gastroenterologists and hepatologists need to be vigilant active advocates for their patients.

\section{REFERENCES}

1. Weiss KH, Thurik F, Gotthardt DN, et al. Efficacy and safety of oral chelators in treatment of patients with Wilson disease. Clin Gastroenterol Hepatol 2013;11:1028-35.

2. Walshe JM. Wilson's disease presenting with features of hepatic dysfunction: A clinical analysis of eighty-seven patients. Q J Med 1989;70:253-63.

3. Czlonkowska A, Litwin T, Karlinski M, Dziezyc K, Chabik G, Czerska M. D-penicillamine versus zinc sulfate as first-line therapy for Wilson's disease. Eur J Neurol January 21, 2014 (Epub ahead of print). DOI: 10.1111/ene.12348 .

4. Roberts EA, Schilsky ML. Diagnosis and treatment of Wilson disease: An update. Hepatology 2008;47:2089-111.

5. Scheinberg IH, Jaffe ME, Sternlieb I. The use of trientine in preventing the effects of interrupting penicillamine therapy in Wilson's disease. N Engl J Med 1987;317:209-13.

6. Kesselheim AS, Solomon DH. Incentives for drug development the curious case of colchicine. N Engl J Med 2010;362:2045-7.

${ }^{1}$ Division of Gastroenterology, William Osler Health Centre, Brampton; ${ }^{2}$ University of Toronto, Division of Gastroenterology, Hepatology and Nutrition, The Hospital for Sick Children, Toronto, Ontario

Correspondence: Dr Natasha Chandok, Division of Gastroenterology, William Osler Health Centre, 2100 Bovaird Drive East, Brampton, Ontario L6R 3J6. Telephone 905-494-2120 ext 57994, fax 905-303-3883, e-mail nchandok@uwo.ca

Received and accepted for publication February 17, 2014 


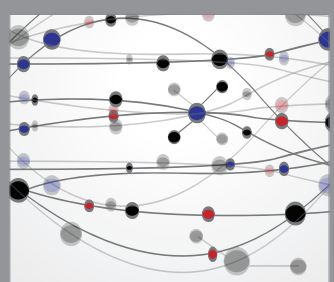

The Scientific World Journal
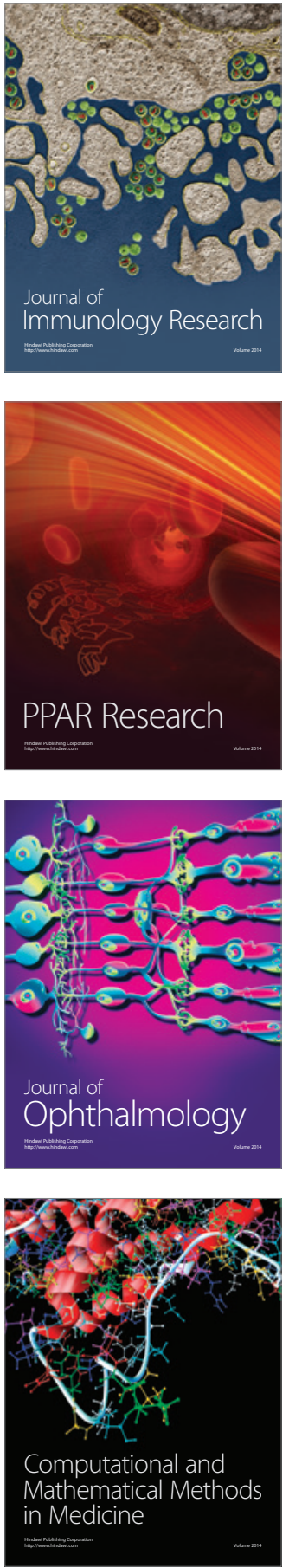

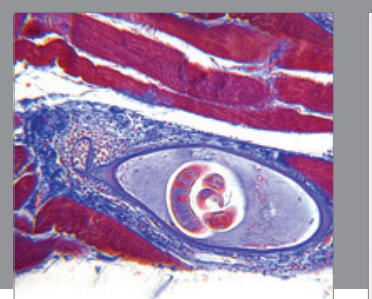

Gastroenterology Research and Practice

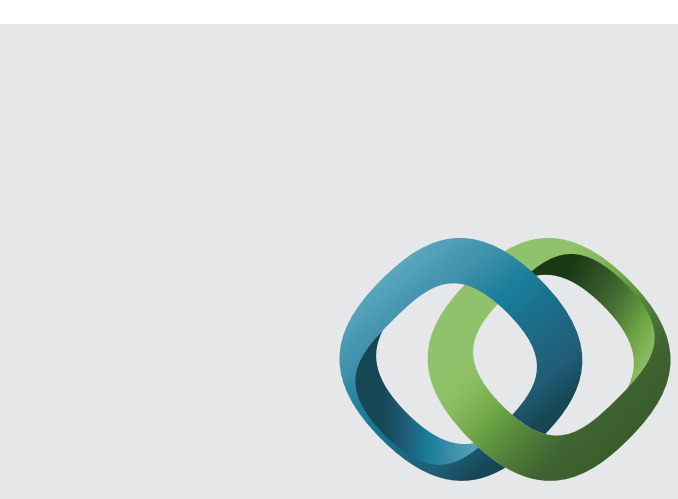

\section{Hindawi}

Submit your manuscripts at

http://www.hindawi.com
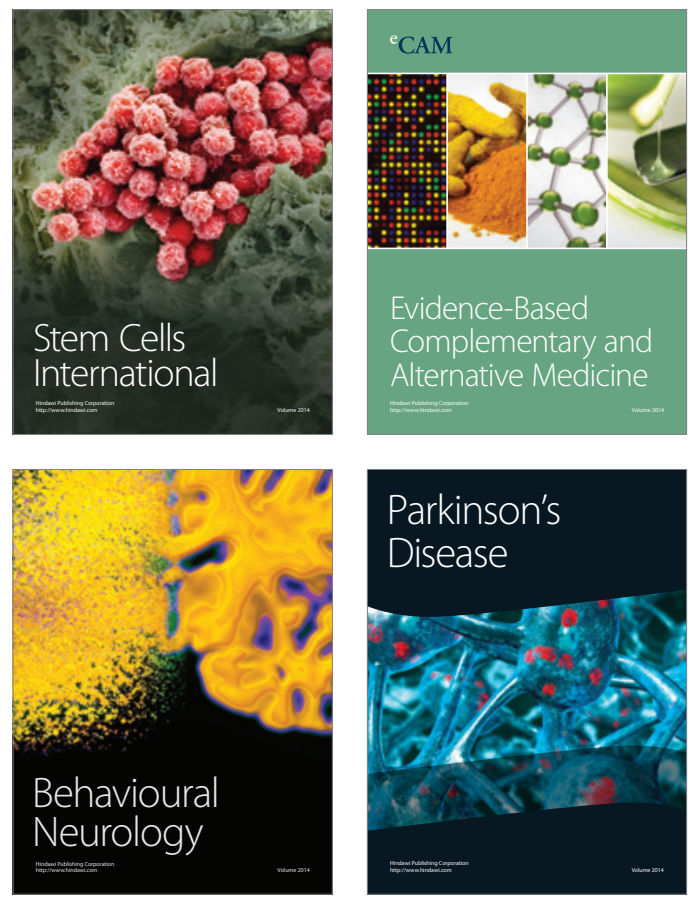
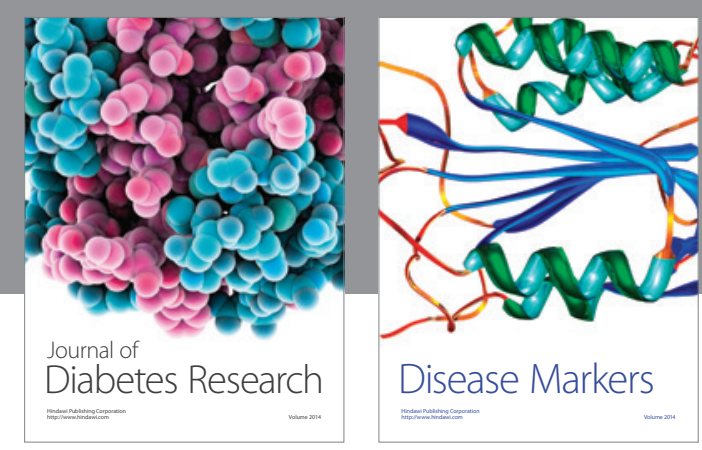

Disease Markers
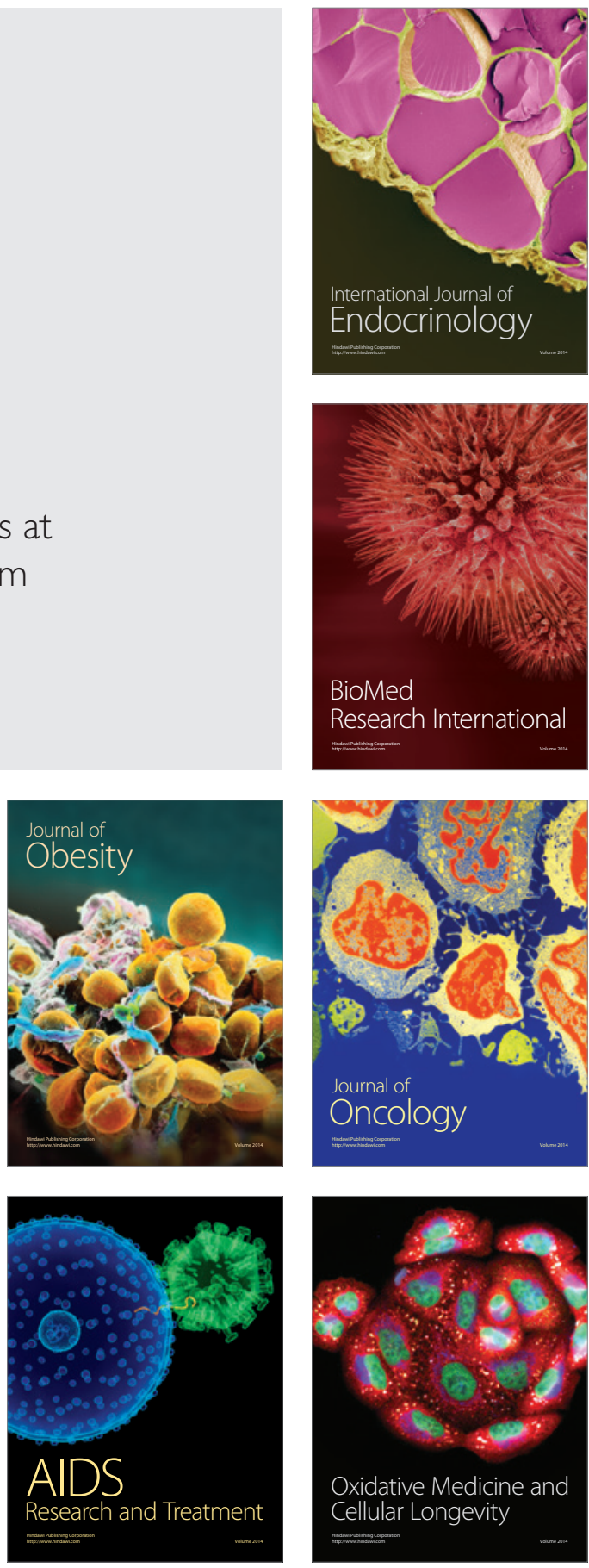